\title{
A cohort perspective of the effect of unemployment on fertility
}

\author{
Héctor Pifarré i Arolas ${ }^{1,2}$ (D)
}

Received: 22 June 2016 / Accepted: 21 March 2017 / Published online: 13 April 2017 (C) The Author(s) 2017. This article is published with open access at Springerlink.com

\begin{abstract}
This work offers an explanation for the apparent contradiction between empirical work that finds a negative relationship between unemployment and fertility, and theoretical work that emphasizes the lower opportunity cost of childbearing while unemployed. I reconcile these perspectives by distinguishing between two forms of unemployment. The first form is structural unemployment, while the second form is cyclical unemployment, a less permanent component of unemployment that is linked to the economic cycle. I apply a cohort-based model to study both effects over the life cycle using panel data methods applied to a sample of developed countries. My results show that higher levels of structural unemployment decrease fertility, but that the effects of cyclical variations in unemployment depend to a large extent on the age at which they are experienced. Cyclical reductions in the unemployment level mostly result in increases in fertility rates. However, for some age groups, positive variations in the cyclical component of unemployment can also have a positive impact on fertility.
\end{abstract}

Keywords Cohort fertility · Unemployment · Countercyclical fertility

JEL Classification $\mathrm{J} 11 \cdot \mathrm{J} 13 \cdot \mathrm{J} 18$

Responsible editor: Alessandro Cigno

Héctor Pifarré i Arolas

pifarreiarolas@demogr.mpg.de

1 Max-Planck-Institut fur Demografische Forschung, Rostock, Germany

2 Center for Research in Health and Economics, Universitat Pompeu Fabra, Barcelona, Spain 


\section{Introduction}

Two broad perspectives feature in the extensive literature on the relationship between economic conditions and fertility. The first studies fertility and the economic cycle as dynamic phenomena in which shifts in fertility affect economic conditions, and vice versa (Lee 1973). As evidence on fertility-based economic cycles has become more tenuous over time (Poterba 2001 and Abel 2001), a second and now dominant perspective that focuses more on the effects of economic conditions on fertility has emerged.

This second perspective has gained momentum in part due to the recent economic recession from 2008 to $2009,{ }^{1}$ which has sparked a renewed interest in the effects of economic conditions on fertility. It is now well understood that long-lasting low fertility rates pose a serious threat to the sustainability of transfer schemes, such as the pension system. The current recession has not only been exceptionally severe, it also started in a period in which fertility rates in developed countries were already low. This coincidence could prove particularly harmful, as the onset of the recession in 2008 may have halted the ongoing recovery of fertility rates (Goldstein et al. 2013).

While there are a number of channels through which economic conditions can affect fertility, current research has highlighted the importance of unemployment (Sobotka et al. 2011). However, even though it is commonly accepted that high unemployment depresses aggregate fertility (Adserà 2005), theoretical models of family decision-making have traditionally emphasized the lower opportunity cost of childbearing during periods of relatively high unemployment and lower income growth (Becker 1981). The aim of this article is to offer insights into the tension between the early theoretical literature that emphasizes the countercyclical effects of unemployment, and more recent empirical findings that indicate that unemployment has a negative impact on fertility. In this work, I seek to reconcile these conflicting findings by considering the cyclical and the structural components of unemployment separately using a new modeling approach. My results suggest that both perspectives are empirically relevant, and that each simply emphasizes one specific side of the relationship between unemployment and fertility. This work therefore helps to answer the question of whether countercyclical fertility is an empirically relevant phenomenon at an aggregate level.

In this work I depart from existing research on fertility and unemployment in two ways. First, I introduce a conceptual distinction between cyclical unemployment and structural unemployment. Using well-established statistical techniques from the business cycle literature, I decompose unemployment into a long-term trend component, or structural unemployment; and a short-term variation in this trend, or cyclical unemployment. My hypothesis is that it is reasonable to expect that families will adjust fertility downward when economic conditions are persistently difficult, but that families might react differently to short-term variations in unemployment. In the next section, I elaborate on how this expectation is well grounded in existing theories of family responses to economic shocks. Second, I suggest a cohort-based model-

\footnotetext{
${ }^{1}$ These are the dates of the economic recession in the USA, according to the National Bureau of Economic Research. Exact periods vary by country.
} 
ing approach, and show how both in theory and in the empirical application it has some advantages over the more traditional models based on lagged unemployment and cross-cohort, age-specific period fertility rates. In my cohort model I study completed fertility for different cohorts in 5-year age groups, and relate it to summary statistics of the history of unemployment experienced by the cohort during the period. This allows me to capture the effects of unemployment over longer time horizons, which is not possible when studying the effect of unemployment in a set period with information on the fertility of several different cohorts.

I empirically address these questions by examining cohorts with birth years from 1958 to 1969 for nine developed countries. I relate the complete histories of fertility and unemployment with panel data methods, and compare the outcomes from standard models and cohort-based models. My findings demonstrate the advantages of using cohort approaches, and confirm my assumption that the distinction between structural and cyclical employment is empirically relevant. Both components of unemployment have a significant statistical influence, often with opposing signs, that vary depending on the age of the mother. Generally, I find that higher levels of structural unemployment are associated with lower fertility, and that the effect of cyclical variations in unemployment on fertility depends primarily on the age at which a woman experiences these variations. Interestingly, I find evidence that temporary increases in unemployment can have a positive influence among the youngest and the oldest age groups. My findings are robust to the inclusion of labor force participation. The paper is organized as follows. First, I discuss the theoretical foundation of my hypothesis and the background literature within which this work is situated. I then present the data together with my operationalization of the research questions and the estimation method. In the next section, I discuss my empirical results. In the final section, I present my conclusion.

\section{Theory and related literature}

Most recent studies that have examined the link between fertility and unemployment have concluded that worsening economic conditions lead to lower fertility. For a recent comprehensive review of the empirical literature, see Sobotka et al. (2011). For instance, Goldstein et al. (2013) found that in the current recession unemployment has had a negative effect on fertility. However, earlier research has shown (Butz and Ward 1979; Ermisch 1988) that in a context in which the level of female labor participation is relatively high, a period of relatively low income growth can lead to an increase in fertility. This empirical result is in line with the findings of theoretical microeconomic models that indicate that recessions are periods during which the opportunity cost of having children for working women diminishes; a phenomenon known as countercyclical fertility (see Becker (1981) and Heckman (2015)).

It is worthwhile to recall that the hypothesis for countercyclical fertility appeared in a context of rapidly increasing female labor force participation and decreasing fertility rates. As it is commonly accepted that opportunity costs are the driving force behind the negative trends in fertility, the natural corollary is that fertility should rise during periods in which the opportunity costs associated with having children are 
relatively low. The negative association between fertility and labor market participation has become an established empirical regularity that has only relatively recently been revised, notably by Ahn and Mira (2002). ${ }^{2}$ The authors pointed out that this negative association was reversed from the late 1980s onward, due at least in part to the effect of unemployment. Currently, the countries with high levels of female labor market participation also tend to be the countries with relatively low levels of unemployment. An example of a possible pathway for this finding was presented in Ahn and Mira (2001). The authors found support for the hypothesis that high levels of unemployment lead to delays in family formation and marriage, and thus for the assumption that unemployment is associated with lower fertility. In light of these and similar findings, there has been a shift away from attributing fertility differentials across developed countries to female labor force participation levels, and toward attributing these differences to unemployment levels.

With the increased focus on the study of the negative impact of unemployment and institutional arrangements (see, for instance, Adserà (2004)), countercyclical fertility has been largely discredited as a major effect. In this paper, I seek to reconcile the tension between these two perspectives by studying the differential effects of the short-term, or cyclical unemployment level; and the long-term, or structural unemployment level. My hypothesis is that, on the one hand, temporary increases in unemployment-which I call the unemployment cycle-can lead to an increase in fertility through a reduction in the opportunity costs associated with children (e.g., foregone wages); and that, on the other hand, high unemployment levels can lead to a decrease in fertility in part because a high level of unemployment makes career interruptions more costly, and diminishes the permanent income of the family. I include both effects in my models. My findings indicate that both the cyclical and the structural component effects of unemployment are statistically significant. Moreover, I find evidence that, at least for certain age groups, countercyclical fertility is the dominant force.

This hypothesis of a differentiated effect of the two components of unemployment is well grounded in a variety of theoretical mechanisms. In this work, I review mechanisms that build on the traditional analysis of fertility decisions in terms of income and substitution effects. Following the seminal works by Becker (1965) and Mincer (1962), economic downturns have often been modeled with a focus on the allocation of time between home production and participation in the labor market. In this set up, worsening job opportunities have an ambiguous effect on fertility. On the one hand, the expectation of worse labor market outcomes is a negative income effect that could depress fertility as the family lowers the consumption of goods (Lindo 2010), including childbearing. On the other hand, the opportunity cost of childbearing diminishes, since the foregone wages associated with childbearing are lower in bad times; this

\footnotetext{
${ }^{2}$ There is still considerable controversy surrounding the question of whether the relationship between labor market participation and fertility has changed sign from negative to positive. For instance, Kögel (2004) found no evidence of this change using time series data.
} 
constitutes the so-called substitution effect. While typically this analysis has been used for changes in wages, it can be readily applied to the effect of unemployment. Arguably, it is possible to consider an increase of unemployment as a decrease in the expected wage of an individual.

In order to investigate the differential effects of cyclical and structural unemployment, however, it is necessary to introduce longer time horizons. Indeed, it is precisely in the context of life cycle considerations that the persistency of unemployment becomes relevant. My hypothesis is that families do not perceive temporary variations of unemployment to be as harmful to the family's budget as structural unemployment. I present two basic mechanisms through which the distinction between cyclical and structural is relevant.

The first mechanism is a straightforward extension of the traditional model that operates through distinct income effects between the two types of unemployment. The basic premise is that the occurrence of cyclical unemployment does not necessarily alter the expected life-time income of a family, while structural unemployment would. For that reason, the income effect would dominate for changes in structural unemployment, whereas the relatively weaker income effect of cyclical unemployment would be dominated by the substitution effect. Thus, the lower fertility rates observed in countries with persistently high levels of unemployment may be attributable to structural unemployment. In contrast, a temporary increase in unemployment may cause a countercyclical fertility response.

The second mechanism builds on the intertemporal considerations by including the long-lasting consequences of career interruptions. According to some research (Adserà 2004), career interruptions are particularly harmful in a context of continual high unemployment. For instance, Hotchkiss and Pitts (2007) have documented how frequent interruptions negatively influence job market outcomes. In addition, (re)entering the labor market in periods of high unemployment is associated with heavy, long-lasting penalties (for instance, see Oreopoulos et al. (2012) for an analysis on college graduates). A weaker commitment to the labor market can appear particularly unappealing from a long-term perspective and in a context in which structural unemployment is high. Even should a woman face lower immediate opportunity costs associated with childbearing, the conjecture here is that the difficulties she anticipates experiencing as she attempts to re-enter the labor market are likely to dominate her decision about whether to have a child. Thus, it is important to consider longer time horizons when considering the substitution effects associated with unemployment.

The cohort perspective I take in this work is particularly well-suited to investigating the life cycle effects of unemployment. Since I track the fertility and unemployment histories of the cohorts throughout their entire fertile lives, I can include measures of both contemporary and past unemployment in my models. This facilitates the distinction between the effects of cyclical and structural unemployment; as I illustrate in this work, they require longer time horizons for identification. Other work has exploited the cohort perspective to explore other aspects of the relationship between unemployment and fertility. An active research agenda using the cohort approach deals with the distinction between the permanent and the temporary 
effects of unemployment. ${ }^{3}$ Neels et al. (2013) found evidence of postponement using a microeconometric model that related the level of unemployment at younger ages with increases in the probability of the occurrence of a first birth at later ages. Recent work by Currie and Schwandt (2014) has also investigated whether unemployment leads to permanent or temporary reductions in fertility in a cohort setting. The focus of the authors was, however, on completed fertility. By linking unemployment at different ages with the completed fertility of a cohort, they showed that, while there was some degree of postponement, the overall effect of unemployment on fertility was negative. One of the findings in my work suggest that while the overall effect on completed fertility is negative, there might be some recuperation at older ages, as in Neels et al. (2013). A detailed study of the tempo and quantum effects of unemployment, however, is beyond the scope of this work.

\section{Data and methods}

\subsection{Data and descriptive statistics}

I use data on cohort age-specific fertility rates from various countries gathered in Myrskylä et al. (2013), which are predominantly available online. ${ }^{4}$ The data consist of the complete fertility histories between ages 15 to 39 for 12 cohorts born between 1958 and 1969 in nine developed countries (detailed in Table 1). This corresponds to 37 years of data in period terms. A problem that can arise in a cohort-level analysis is that it can be difficult to obtain data on enough cohorts with completed fertility to perform a rigorous statistical analysis. The choice of countries and the period of study was heavily influenced by this constraint. ${ }^{5}$

The data include information on fertility rates from 1973 to 2008. For a given cohort, I have information on the number of births per 1,000 women for all years between ages 15 and 39. For the sake of tractability, this variable is divided into five age groups: 15 to 19,20 to 24,25 to 29,30 to 34 , and 35 to 39 . While unemployment has been shown to have differentiated impacts across birth orders (Hoem 2000, Andersson 2000 and Goldstein et al. 2013), in this work birth order is not considered due to constraints on the availability of parity-specific fertility rates for earlier cohorts.

A key issue in the estimation is how to properly account for fertility trends. In the period considered, most of the countries in this study are experiencing both general delays and reductions in fertility. Figure 1 plots the cohort completed fertility for the 12 cohorts at age 39 . The figure shows a general decrease in completed fertility

\footnotetext{
${ }^{3}$ The so-called tempo and quantum effects of unemployment have also been studied from a period perspective in Goldstein et al. (2013).

${ }^{4}$ The majority of the data in the article are from the Human Fertility Database and Eurostat, although for some of the countries Myrskylä et al. obtained data via personal communication. All data used in this paper are detailed in the Appendix and are additionally directly available upon request.

${ }^{5}$ In addition, a further constraint was the availability of gender- and age-specific unemployment rates, which were used in a number of robustness checks.
} 
Table 1 Countries used in the analysis and data sources

Data were collected in Myrskylä et al. (2013) and made available to us by the authors. Human Fertility Database (HFD) data are obtained from http://www. humanfertility.org.

\begin{tabular}{ll}
\hline Country & Source \\
\hline Australia & Statistics Australia \\
Finland & HFD \\
Italy & Eurostat \\
Japan & Personal communication \\
Netherlands & HFD \\
Norway & HFD up to 2006, 2007-2009 Eurostat \\
Spain & HFD up to 2006, 2007-2009 Eurostat \\
Sweden & HFD \\
USA & HFD \\
\hline
\end{tabular}

across cohorts for most countries. The two extreme cases are Japan, with a very significant drop; and the USA, which has a slight increase over the period. In between there are countries with almost constant fertility rates, such as Norway; and others, like Sweden, with slight decreases. I also observe delays for all countries in the timing of fertility during this period. This can be seen more clearly in Fig. 1 (right panel), which displays cumulated fertility as a proportion of completed fertility of the cohort from ages 12 to 40 for the USA and Japan in 1957 and in 1969. Despite the delays in timing, the results indicate that fertility beyond age 39 still represents

a

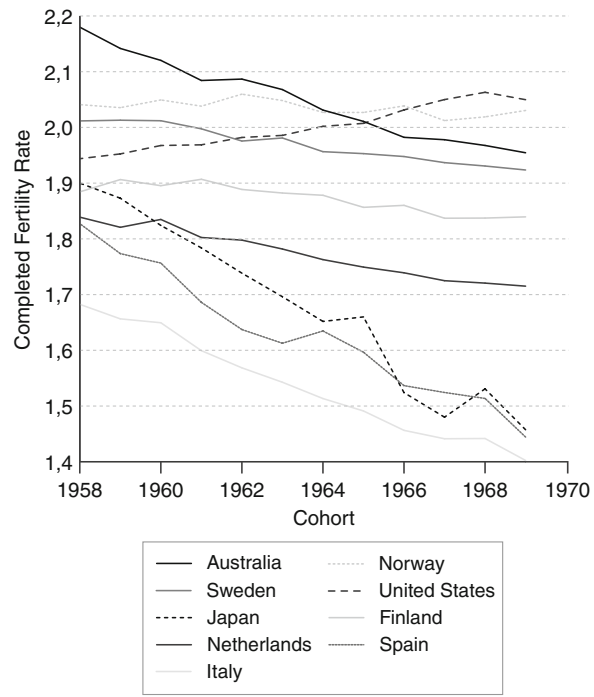

b

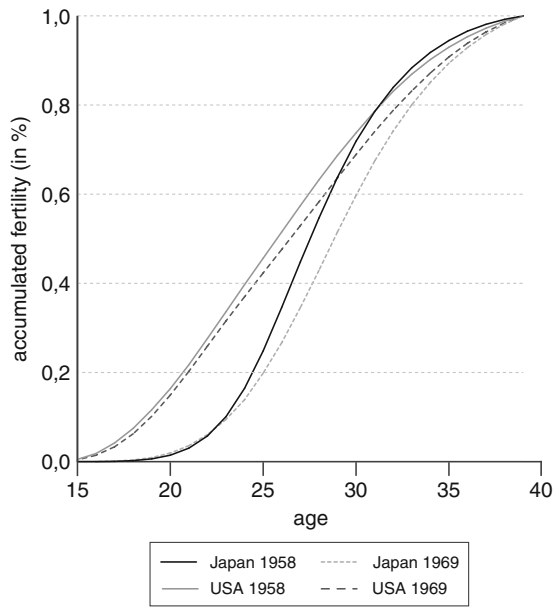

Fig. 1 The figure on the left side shows the completed fertility rates of the nine developed countries used in the analysis (cohorts from 1958 to 1969). The figure on the right side displays the cummulative fertility rates of the USA and Japan for the cohorts of 1958 and 1969 
a very small fraction of completed fertility. For example, for the 1968 cohort in the USA, fertility beyond age 39 represents under five percent of the cohort's completed fertility.

The series on unemployment rates is from the online repository of the Organization for Economic Cooperation and Development (OECD) for the period 1971-2008. Figure 2 displays the total yearly unemployment for the nine countries. While it is possible to observe some common trends in total unemployment across countries, there is wide heterogeneity in unemployment levels. For example, for most of the considered period Spain had unemployment rates that were several times higher than those of the countries with the lowest unemployment levels. In general, however, I find an increasing trend in unemployment for all of the countries, together with a wider dispersion of unemployment rates across countries. To decompose unemployment into its structural and cyclical components, I use a standard Hodrick-Prescott filter (Hodrick and Prescott 1997). Following Ravn and Uhlig (2002), the smoothing parameter is adjusted to account for annual data $(\lambda=6.25)$.

\subsection{Modeling}

In this work, two families of models are estimated and compared: period-to-period models (PtP) and cohort models. PtP models typically relate fertility in a given period with unemployment lagged by 1 year; the convention is that it is necessary to allow for a year for conception and gestation (McDonald 1983). This modeling approach is not restricted to macro-level studies (Butz and Ward 1979; McDonald 1983; Ermisch 1988; Ahn and Mira 2002; Goldstein et al. 2013), and can be relevant for individual or family-based models that link particular histories of unemployment and fertility (Neels et al. 2013). A feature of the PtP approach is that it focuses on the

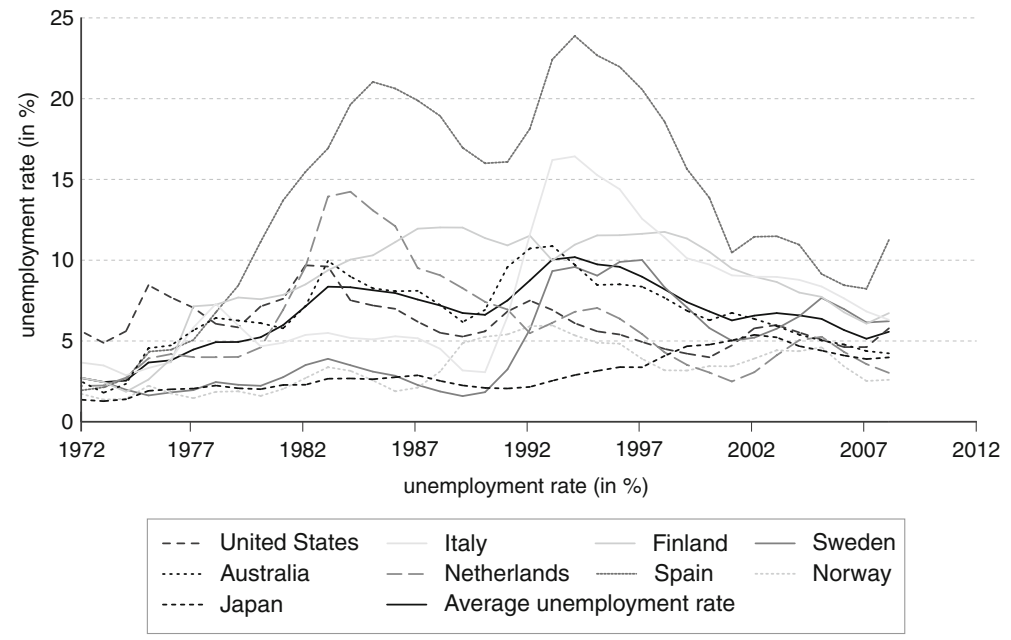

Fig. 2 This figure shows the unemployment rates of the nine developed countries used in this study (from year 1972 to 2008). It also includes the average unemployment rate across countries 
almost instantaneous effect of unemployment on fertility, and thus might not capture all of the possible complex relationships between unemployment and fertility. While it is clear that PtP modeling may have trouble distinguishing the quantum and the tempo effects of unemployment, it may also be limited by its characterization of the instantaneous influence of unemployment. It is natural to assume that families might not have the ability to foresee the extent to which variations in contemporary unemployment rates are temporary or structural, and that these changes might therefore have no immediate effect on their fertility decisions, which is not accounted for in PtP models. While cohort models do not explicitly model families categorizing observed unemployment as short- or long-term, because they allow for a longer time horizon between observing and categorizing, cohort models are more likely to capture families distinguishing between the two types of unemployment. My contention is that fully capturing more complex relationships between fertility and unemployment is crucial for identifying the countercyclical effects of unemployment.

In this context, cohort-based approaches can address some of the shortcomings of PtP modeling. A cohort model follows a group of individuals-in this case an age cohort-over time, and relates the cohort's unemployment and fertility histories. It is possible to accommodate the longer term effects of unemployment in such models, while avoiding mis-categorizing or confusing tempo and quantum effects; this is the strategy followed by Currie and Schwandt (2014). Here, I study the impact of unemployment on the completed fertility of a number of age groups as a function of the history of unemployment experienced during those years. In my main models, each age group is related to unemployment during the potential years of conception. However, as a robustness check, I also estimate models that include the whole history of unemployment, up to the age considered. In this section, both approaches are developed and compared from a theoretical standpoint.

\subsubsection{Period-to-period models}

PtP models study the effect of unemployment, typically lagged by one period and decomposed into its two components (structural and cyclical), on the age-specific period fertility of a given age group. That is, age groups are modeled separately. In this framework, the fertility of an age group is composed of the sum of the agespecific fertility rates of the individuals within the lower and upper limits of the age group in a given year. Equation 1 describes a PtP model, inclusive of country fixed effects and a linear time trend for age group $a \in(1, \ldots, 5)$, period $t$, and country $k \in(1, \ldots, 9)$ :

$$
F_{a, k, t}=\alpha_{a, k, t}+\delta_{a, k} t+\beta_{a} u_{a, k, t-1}+\gamma_{a} p_{a, k, t-1}+\theta_{a} n_{a, k, t-1}+e_{a, k}
$$

where $\alpha_{a, k}$ is an age-specific country fixed effect and $\delta_{a, k}$ is the coefficient for the linear country and age group-specific trend. $u_{a, k, t-1}$ is the structural component of unemployment, lagged by one time period. Finally, the terms $p_{a, k, t-1}$ and $n_{a, k, t-1}$ separately capture the positive and negative variations (cyclical) in unemployment, respectively. 


\subsubsection{Cohort models}

In contrast, cohort models follow a particular birth cohort over a number of years, and relate the cohort's unemployment and fertility histories. Take, for example, a cohort composed of individuals who were age 20 in 1980. The cohort approach models the effect of unemployment between ages 19 and 24 (1979 to 1984) on cumulated fertility from ages 25 to 29 (1980 to 1985). Cumulated fertility is defined here as the sum of the age-specific cohort fertility rates between the years 1980 and 1985 for this cohort. In general, I model completed fertility over the years of an age group as a function of summary statistics of the unemployment components of the period. More formally, for age group $a \in(1, \ldots, 5)$, country $k \in(1, \ldots, 9)$ and cohort $c \in(1, \ldots 12)$ the main model, cohort-sans-history $(\mathrm{CsH})$, estimates the age group cumulative fertility in the following way:

$$
\mathrm{CF}_{a, k, c}=\alpha_{a, k}+\delta_{a, k} t+\beta_{a} \bar{u}_{a, k, c}+\gamma_{a} \bar{p}_{a, k, c}+\theta_{a} \bar{n}_{a, k, c}+e_{a, k, c}
$$

The dependent variable is the cumulated fertility of age group $a, \mathrm{CF}_{20, k, c}$ and captures the sum of age-specific fertility rates strictly for the years that form the age group. The term $\alpha_{a, k}$ is an age-specific fixed effect and $\delta_{a, k}$ is again the linear trend. In this case, time is measured in terms of cohorts. In this cohort model the measurement of unemployment is different. While unemployment is measured in its total or decomposed form and is lagged by a 1-year period in the PtP models, the $\mathrm{CsH}$ models presented here consider unemployment measures that capture the last 5 years of unemployment history. These are the years for which cumulated fertility is considered, also lagged by 1 year to allow for gestation.

To avoid an excessive number of parameters that would quickly hinder estimation with a small sample size, ${ }^{6}$ a parsimonious, one parameter representation of each component of unemployment is modeled. It is important to note that without this simplification there would be 15 unemployment variables. In the case of structural unemployment, $\bar{u}_{a, k, c}$, the mean value across the 5 years of the period is used with a general one year lag. The positive and negative cyclical components, $\bar{p}_{j, k, g}$ and $\bar{n}_{j, k, g}$, respectively, are measured through the simple sum of each year's value over the period, again lagged 1 year with respect to fertility. ${ }^{7}$ While the mean might be a reasonable representation for the more stable structural unemployment, using it for the cyclical component would imply excessively low levels of cyclical variation. The sum is a better representation of the intensity of the unemployment shocks a family might have suffered during the period under study.

Finally, in order to study the robustness of $\mathrm{CsH}$ models to the inclusion of longer indirect effects of unemployment on fertility, I estimate a cohort model with history

\footnotetext{
${ }^{6}$ Here the small sample size is $n=96$.

${ }^{7}$ Note that the unemployment variable corresponds to period specific unemployment data for the years during which the cohort was in the corresponding age group.
} 
$(\mathrm{CwH})$ that includes the full history of unemployment. For instance, for the second age group (ages 20 to 24), the model is the following:

$$
\begin{gathered}
\mathrm{CF}_{24, k, c}=\alpha_{a, k}+\delta_{a, k} t+\beta_{24} \bar{u}_{19, k, c}+\beta_{24} \bar{u}_{25, k, c}+\gamma_{24} \bar{p}_{19, k, c}+\gamma_{24} \bar{p}_{25, k, c} \\
+\theta_{24} \bar{n}_{19, k, c}+\theta_{24} \bar{n}_{25, k, c}+e_{25, k, c}
\end{gathered}
$$

where the terms have the same interpretation as from Eq. 2 but with the inclusion of cyclical and structural components of unemployment between ages 15 to $19, \bar{p}_{19, k, c}, \bar{n}_{19, k, c}$, and $\bar{u}_{19, k, c}$, respectively. More generally, the model for age groups beyond the first age group can be written in the following way. For a country $k \in(1, \ldots, 9)$, age group $a \in(2, \ldots, 5)$, and cohort $c \in(1, \ldots 12)$, the sum of the fertility each year of the age interval is estimated from the following model:

$$
\mathrm{CF}_{a, k, c}=\alpha_{a, k}+\delta_{a, k} t+\sum_{i=1}^{a} \beta_{i} u_{i, k, c}+\sum_{j=a-2}^{a-1} \gamma_{j} p_{j, k, c}+\sum_{l=a-2}^{a-1} \theta_{l} n_{l, k, c}+e_{a, k, c}
$$

In general, the $\mathrm{CwH}$ models include the full history of structural unemployment, while the cyclical components are limited to up to two lags to avoid an excessive number of parameters. The interpretation for the coefficients on the lagged values of unemployment is that of a tempo effect.

For example, consider the above example of a $\mathrm{CwH}$ model for the age group 20 to 24 . One of the variables included in the model is the mean level of structural unemployment for ages 15 to 19 . A positive coefficient on that variable would imply that higher structural unemployment in the previous period leads to an increase in fertility in the contemporary period. Typically, when matched with a negative sign for the model of ages 15 to 19, this could be interpreted as indicative that some of the reductions in fertility for the earlier group were due to the decision to postpone fertility to ages 20 to 24 . That is, they measure whether unemployment early in life triggers the postponement of fertility at a cohort level.

Figure 3 illustrates the possible relationships between unemployment and fertility captured by both models. I denote as direct effects the influence of unemployment on fertility in the following year; and indirect effects the influence of unemployment

Fig. 3 This figure illustrates the direct and the indirect effects of unemployment. $U$ stands for unemployment and $F$ for fertility. Gray arrows denote direct effects and red arrows denote indirect effects. Subscripts indicate the ages, e.g., $U_{14}$ is unemployment measured in age 14

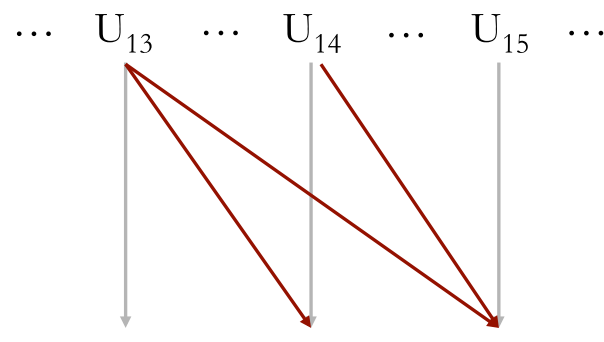

$\begin{array}{llllllll}\ldots & \mathrm{F}_{14} & \ldots & \mathrm{F}_{15} & \ldots & \mathrm{F}_{16} & \ldots\end{array}$ 
on fertility in subsequent years. The total effect is defined as the sum of direct and indirect effects.

Given that the PtP and the CsH models approach the same question from different angles-i.e., what is the effect of unemployment on fertility-it is reasonable to expect the models to deliver similar (or the same) answers, at least under certain circumstances. In the $\mathrm{CsH}$ model presented here, this is the case when unemployment only has direct effects on fertility. However, given that we know that at least some indirect effects do indeed exist (Neels et al. 2013), we would not expect this equivalence to hold in practice.

Finally, even if it is the case that the complexity of the effect of unemployment on fertility might require longer horizons than one lag, it could be argued that this is not a reason to move toward a cohort analysis. After all, it is possible to include more lags in an standard analysis by age groups. My claim is that in doing so, we move precisely towards cohort models. To see why, consider a single age fertility model; for instance, fertility at age 20 . This is not unreasonable, since modeling fertility by age groups instead of by single ages is, after all, a matter of convenience (e.g., not having 40 models to read and interpret), and not a substantive decision. It is indeed possible to add further past values of unemployment to a single age fertility model. For example, it is possible to model fertility at age 20 in the year 2000 as a function not only of unemployment in the year 1999, but also in the year 1998 and in further lags. However, the model then automatically becomes cohort based, as the analyst would be tracking an age cohort over time. The models proposed in this paper are an extension of this reasoning to the common practice of grouping ages for analysis.

\section{Results and discussion}

\subsection{Results}

To establish the utility of cohort models in measuring the effect of unemployment on fertility, PtP models were compared with $\mathrm{CsH}$ models. The results of this comparison show that these models fail to capture the significant relationship between fertility and the cyclical components of unemployment. This reliance on hypothesis testing means that it is of crucial importance that we not only ensure the consistency of the estimator, but also that we correct the estimation of standard errors. A variety of tests, detailed in the following lines, show that the standard estimates of the variance are not valid. The data display heteroskedastic tendencies (Breusch and Pagan (1979) test) and serial correlation (via Wooldridge (2002) test). Finally, a test for cross-sectional dependence is implemented, as it is likely that the developed countries of the sample have cross influences. The results of a Breuch-Pagan LM test (Breusch and Pagan 1980) indicate that the estimates are not independent. To correct for these issues, I estimate my model using Driscoll and Kraay (1998) standard errors. Driscoll and Kray's standard errors are designed to deal with dependence between cross-sectional units, while also allowing for corrections for temporal dependence and heteroskedasticity. In particular, I estimate a fixed effects within model using the Stata implementation by Hoechle (2007). 

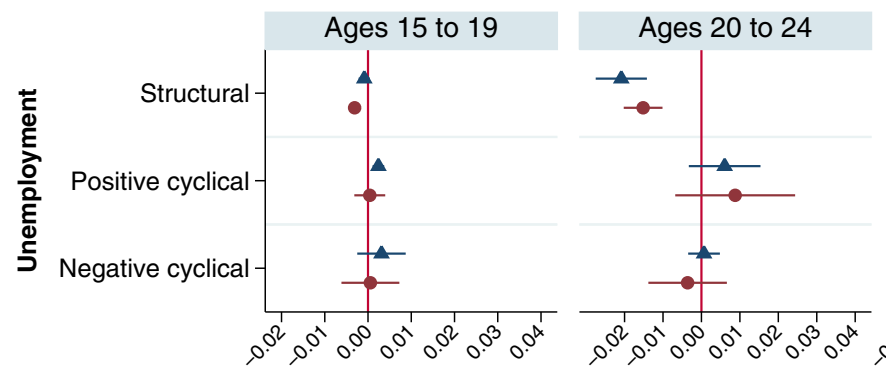

Ages 25 to 29
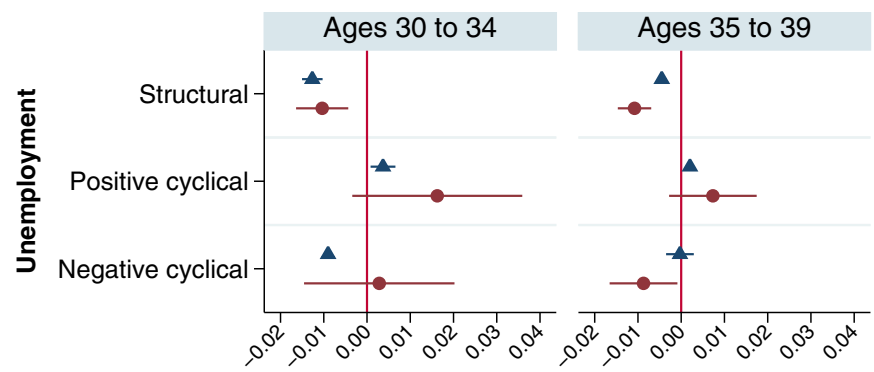

\section{$\triangle \mathrm{CsH} \bullet \mathrm{PtP}$}

Fig. 4 Comparison between PtP and $\mathrm{CsH}$ models. Lines represent 95\% confidence intervals while white dots are point estimates

\subsubsection{Period-to-period and cohort-sans-history}

Figure 4 displays the results of the main models for the five age groups under study. ${ }^{8}$ The figure reports the point estimates and confidence intervals of the cyclical and structural components. The estimates of the "Structural", "Positive cyclical", and "Negative cyclical" components of unemployment correspond to parameters $\beta_{a}, \gamma_{a}$, and $\theta_{a}$ in Eqs. 1 and 2, for PtP and CsH models, respectively. For ease of interpretation, the original variable that captures temporary reductions in unemployment is recoded to its absolute value. Hence, a positive effect of a "Negative cyclical" reduction in unemployment should be interpreted as a temporary reduction of unemployment leading to higher fertility.

A striking difference between the two modeling approaches is that whereas the $\mathrm{CsH}$ models reveal the separate impacts of the cyclical components of unemployment, the PtP models fail to capture these effects. Across age groups, in the PtP models temporary variations in unemployment are clearly not significant. Moreover, by construction, the PtP models have sample sizes that are three times larger than those of the $\mathrm{CsH}$ models. Hence, the lack of significance cannot be attributed to a lack of power in the PtP models.

\footnotetext{
${ }^{8}$ The point estimates of the main models are reported in Table 2 in the Appendix.
} 
In line with the conclusions of previous studies, I find that the structural component has a negative effect in the majority of age groups across both specifications. The results also lend support to the main hypothesis of this paper regarding countercyclical fertility. Across age groups, temporary increases in unemployment are associated with fertility increases; this result is statistically significant for several age groups. However, the effect of the different unemployment components is moderated by age.

The results of the first model (ages 15-19), shown in the first panel of Fig. 4, highlight the importance of the cyclical component. Not only is the structural component of unemployment not significant in the $\mathrm{CsH}$ model, which could be attributed to a lack of power, but the size of the impact of temporary increases in unemployment is considerably larger (this can be better appreciated in Table 2 of the Appendix). The second model (ages 20-24), shown in panel 2, is another good example of how the impact of the different components of unemployment can vary greatly according to age. The impact of the trend component is much larger than for the previous age group, and is the largest across all ages. By contrast, none of the cyclical components have a significant impact. In the case of positive cyclical unemployment, however, this might be related to a lack of power.

The importance of cyclical components resurfaces in the third model (ages 25-29), in which both temporary reductions in unemployment and the structural component have effects of a similar magnitude. For this age group, temporary reductions in unemployment lead to an increase in fertility. Interestingly, the structural component also has a positive impact on fertility in the $\mathrm{CsH}$ models. This is the only age group for which I obtain this result, which I discuss in the context of my robustness checks.

The last two models (ages 30 to 34 and 35 to 39), have common patterns in the effect of the structural and positive cyclical unemployment. In both cases, structural unemployment depresses fertility and there are significant countercyclical effects. There are, however, two important differences. The magnitude of the negative impact of structural unemployment is considerably smaller for late-age fertility (ages 35 to 39) than for the other age groups. Also, a temporary reduction of unemployment is associated with a reduction in fertility. This result, however, should be taken with care as robustness checks show that it is sensitive to several modeling choices (see section on additional robustness checks for more detail).

Generally speaking, the results are consistent with the predictions of the theoretical mechanisms presented in the first part of the paper. Structural unemployment has a negative impact at most ages, as would be expected from its relatively strong negative income effect. At the same time, cyclical increases in unemployment can increase fertility, consistent with a relatively stronger substitution effect.

The mechanism that emphasizes career considerations is helpful to interpret the age patterns of the results. Setting aside for the moment the results for ages 15 to 19 and 25 to 29, the findings in terms of countercyclical fertility are broadly consistent with the differential age-effects of such models. Following Adserà (2004), if labor market experience has diminishing returns, career interruptions earlier in life have a stronger negative effect in the expected lifetime income. Thus, when facing cyclical unemployment, the opportunity cost of childbearing is lower for older ages. This is consistent with my finding that countercyclical fertility is not significant for ages 
20 to 24 and 25 to 29, but appears to be so for the last two age groups (ages 30 to 34 and 35 to 39). At the same time, we should expect stronger negative effects of structural unemployment for younger families with less established careers. Younger non-tenured workers are more vulnerable to unemployment shocks, which is consistent with my finding that the strongest effect of the structural component is for the 20-24 age group.

Nevertheless, some age groups (ages 15 to 19 and 25 to 29) do not fit these narratives. Perhaps this is less surprising for the youngest age group, since families having children at those ages are likely to have a very specific set of circumstances and preferences. The results for the third age group (20 to 24) also deviate from the narrative, but, as I will discuss in the section devoted to robustness checks, they are not significant in certain model specifications.

\subsubsection{Labor force participation, cohort-with-history, and additional robustness checks}

While this article and recent research have focused on unemployment, traditionally research on the relationship between economic conditions and fertility has emphasized the role of participation (this was, for example, central to the work of Butz and Ward (1979)). It was hypothesized that it was particularly in a context of high participation that we might observe countercyclical fertility. In addition, since we know that changes in the level of labor participation are part of the standard response to worsening economic conditions (Murphy and Topel 1997), it is important to account for possible differences in the labor supply response across countries.

In order to address these concerns, I add labor force participation levels to the main models $(\mathrm{CsH})$ as a control. Participation variables are coded similarly to the trend in unemployment; as a 1 year lagged average over the 5 years for each age group. I estimate two separate versions of the models, with the overall level of participation, and with age-specific participation (see Fig. 5). ${ }^{9}$

The main findings of the models presented in the previous section remain. While the effect of the structural component is lessened in some models, it remains generally associated with lower fertility. At the same time, the positive effect of unemployment for ages 25 to 29 is not robust to the inclusion of the general level of participation. Most importantly, the countercyclical effect of temporary increases of unemployment is generally robust to the inclusion of participation. Finally, a temporary reduction of unemployment was associated with lower fertility for the age group 30 to 34, but this effect is lessened once we control for participation, and it becomes non significant when we consider age-specific participation.

A natural extension of the $\mathrm{CsH}$ model is to allow for the whole history of unemployment to influence fertility, here denoted as the cohort-with-history $(\mathrm{CwH})$ model.

\footnotetext{
${ }^{9}$ The results, in particular with regard to the significance of the variables, have to be interpreted with caution. As expected, there is a strong association between labor force participation and the unemployment variables, in particular, the structural component. Given the small size of the sample, this leads to collinearity issues (between the labor and unemployment variables), widening some of the confidence intervals.
} 

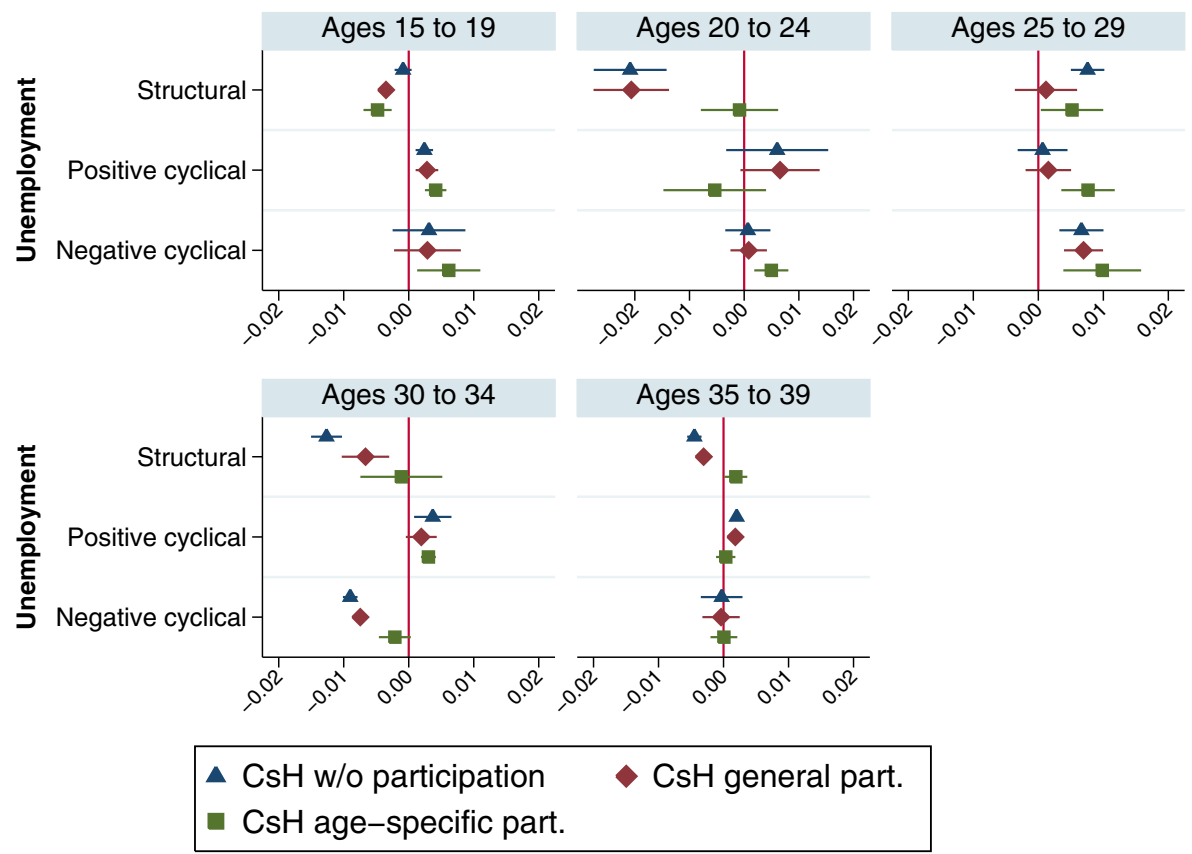

Fig. $5 \mathrm{CsH}$ models controlling for labor participation. Lines represent $95 \%$ confidence intervals and dots point estimates

Given the larger number of parameters estimated over a very small sample, in this work $\mathrm{CwH}$ models are only interpreted as an additional robustness check. The results are displayed in Fig. 6, which illustrates the coefficient estimates for Eq. 4. The interpretation of Fig. 6 is similar to that of Fig. 4, but in this case triangles represent the coefficients of the contemporary variables, and the circles the coefficients capturing the effect of the unemployment history. It is reasonable to expect that episodes of unemployment might have lasting effects on the fertility decisions of the family; that is, that the indirect effects of unemployment might be pervasive.

Qualitatively speaking, the results of the CsH models carry on in this setting. This addresses the possible concern that some of the results in $\mathrm{CsH}$ models were affected by the lack of variables on longer term indirect effects due to data constraints. Particularly, this is also the case for the findings regarding countercyclical fertility. In addition, the general pattern of stronger negative effects of structural unemployment at younger ages (20 to 24), and the presence of countercyclical fertility for early and late life fertility, remained unchanged with the inclusion of longer histories of unemployment. Finally, and while this result should be interpreted with caution, long-term indirect effects seem arise from the structural component of unemployment, mirroring the findings of Neels et al. (2013). Experience of structural unemployment early in life (ages 15 to 19) had a negative impact on fertility between ages 20 and 24 (Fig. 6), but this effect became positive in the model for ages 30 and 34 . This is consistent with a pattern of postponement and recuperation, although here I do not study 

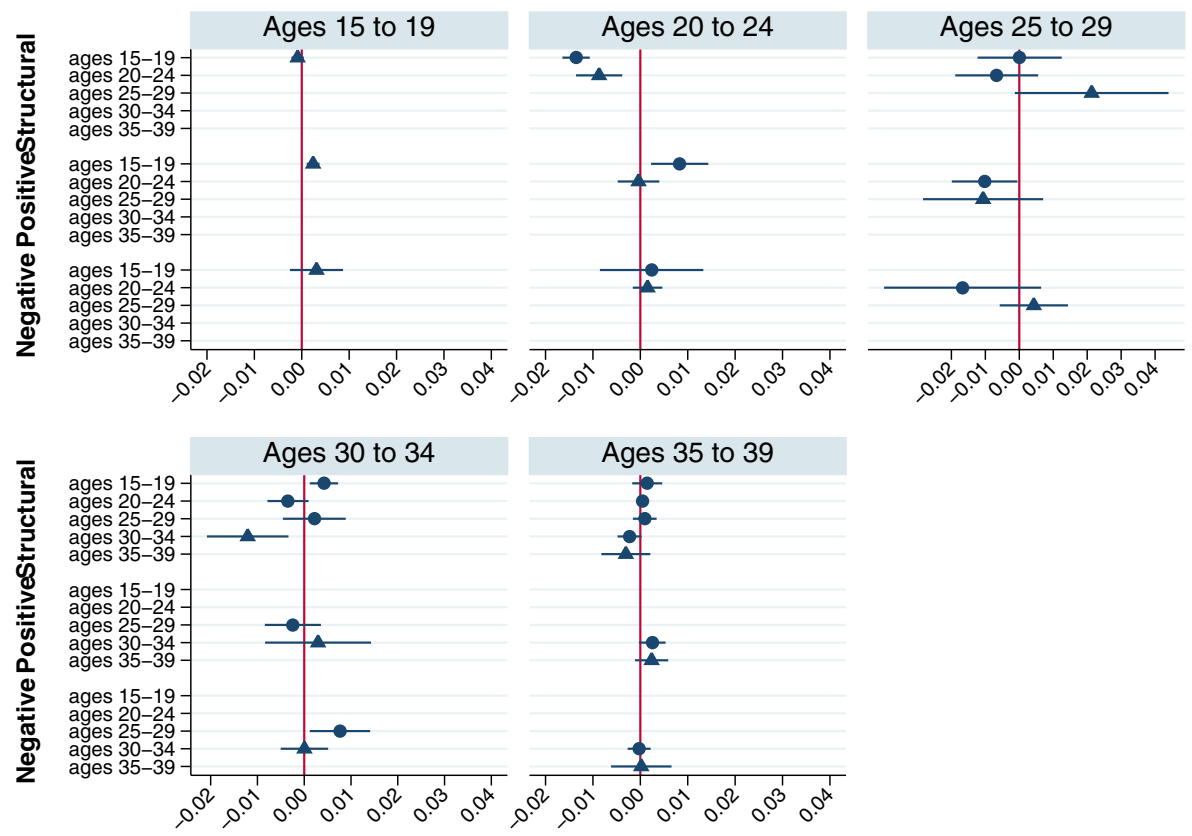

Fig. $6 \mathrm{CwH}$ models. Lines represent $95 \%$ confidence intervals and dots point estimates

the implications for completed fertility (see Currie and Schwandt (2014) for such a discussion).

The results are also qualitatively similar across a number of additional robustness checks (see Tables 2, 3, and 4 in the Appendix for an overview of the robustness checks). First, different countries are excluded in further robustness checks that test the sensitivity of the findings to potential outliers. More importantly, the existence of countercyclical fertility also holds in specifications that use age-specific unemployment and in models with gender-specific unemployment. The assumption of a linear trend does not seem to alter the results either; earlier versions of this paper estimated the model in a Bayesian framework with a non-parametric trend, and the qualitative findings were similar. Finally, an earlier version of the paper used a cruder ${ }^{10}$ decomposition of unemployment into its cyclical and structural components, and the results still showed the importance of countercyclical fertility responses.

\subsection{Comments on the interpretation of the results}

Taken together, the results presented lend support to the hypothesis that, in studying the impact of unemployment on fertility, it is important to distinguish structural and

\footnotetext{
${ }^{10}$ Structural unemployment was defined as the mean of unemployment over the years considered and cyclical unemployment was defined as the sum of the positive and negative variations.
} 
cyclical unemployment. The signs of the effects are consistent with the predictions of models that consider the income and substitution effects on unemployment in a life cycle framework. Structural unemployment is found to have a negative impact on fertility, and there is evidence that there are countercyclical effects for some ages. This is consistent with positive cyclical variations of unemployment having a weaker income effect that structural unemployment, and hence the price of childbearing being lower enough to encourage fertility (a substitution effect). Broadly speaking, the age patterns of countercyclical fertility follow the predictions of models that highlight the impact of career interruptions. Following those models, countercyclical fertility more relevant at older ages, when career interruptions have a lower cost. However, evidence supporting this interpretation is less robust. The non-significance on countercyclical effects at young ages could be related to a lack of power, given the small size of the sample.

A limitation of the cohort design of this work lies in the interpretability of the results in terms of magnitudes. To compensate for the relatively low number of cohorts with completed fertility, cohorts from all countries and periods are pooled together. The resulting average impact estimated is hence difficult to interpret, since it might be detached from the effects experienced by a given cohort or country. Nevertheless, in order to aid in the interpretation of the magnitudes of the results, Fig. 7 describes the effect on fertility of increasing unemployment by one percentage point. In order to provide a reference for the magnitudes, the effects are computed as the

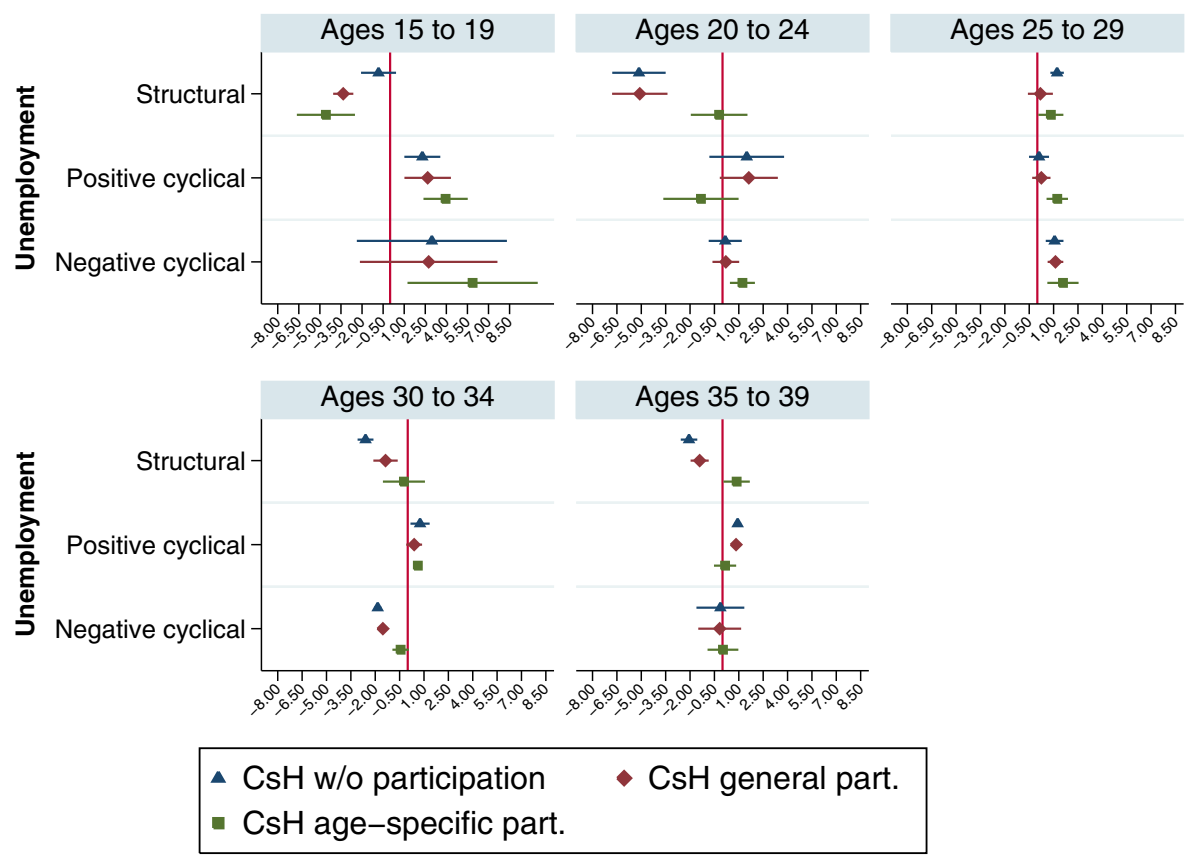

Fig. 7 Effect of unemployment with respect to average age-specific fertility in $\mathrm{CsH}$ models controlling for labor participation. Lines represent $95 \%$ confidence intervals and dots point estimates 
percentage change in the age-specific fertility of an average cohort. ${ }^{11}$ For example, for the age group 15 to 19 , a one percentage point increase in structural unemployment is associated with a decrease in the age-specific fertility of that age group that ranges between 3 and over 4 percent, depending on the model. For that age group, the effect of a positive cyclical increase in unemployment is positive and of a similar magnitude. More generally, structural unemployment tends to have larger effects on fertility than cyclical fluctuations. This difference, however, varies across age groups and is not likely to be significant for certain age ranges. ${ }^{12}$ Some caveats are in order to properly interpret these magnitudes. First, some age groups concentrate a higher proportion of the completed fertility of a cohort. Hence, while fertility might be highly affected by unemployment within the age group, this might not be the case for the overall cohort completed fertility (see Fig. 8 in the Appendix for the same exercise using cohort completed fertility as the reference). Second, there has been a steady trend of postponement of fertility to older ages; for certain age groups, the magnitude of the effect has changed over time with respect to the predicted fertility.

The finding that both cyclical increases and reductions in unemployment have similar effects on fertility might appear contradictory at first sight. We observe a positive effect on fertility of both a cyclical increase and a cyclical reduction in unemployment, which appears to be evidence of heterogeneity in the fertility responses of families to unemployment. This heterogeneity is not surprising from the standpoint of the conventional unitary models of family decisions reviewed in this paper. According to this theoretical framework, countercyclical effects take place in a context of relatively high female labor participation. At a family level, the substitution effects leading to countercyclical fertility only occur when the female partner is also working. If that is not the case, then not only cyclical unemployment does should not lead to higher fertility, but we could also expect a positive effect of temporary reductions in unemployment. The reason for this latter effect is that a temporary reduction in unemployment is a positive income effect for the family, with no negative substitution effect in terms of the opportunity cost of childbearing. Both effects are observed in my results. Given that this work considers relatively older cohorts, with lower levels of female labor market participation, this could be because both types of families are present in the data in significant numbers.

\section{Discussion}

In this work, I have explored the hypothesis of countercyclical fertility by linking the complete fertility and unemployment histories of 12 cohorts in nine developed countries. A decomposition of unemployment into its cyclical and structural components, together with the application of a cohort modeling approach, offer novel insights into the relationship between unemployment and fertility. Notably, this approach

\footnotetext{
${ }^{11}$ I compute the predicted age-specific fertility for an age group according to the baseline model for each cohort, and then average it across the 12 cohorts and nine countries.

${ }^{12}$ For instance, the two younger age groups have different point estimates but also particularly large confidence intervals.
} 
reconciles the seeming contradictions in the results of earlier theoretical literature on family decisions and of recent work showing that unemployment has a negative influence on fertility. While the findings of my analysis are only suggestive of the mechanisms behind countercyclical fertility, they show that countercyclical fertility is statistically significant across a variety of specifications and variable definitions. This work is thus a first step toward establishing that countercyclical fertility is of sufficient quantitative importance to merit further analysis. My findings on the negative effect of structural unemployment are well aligned with the existing literature. However, my use of the cohort-based approach also confirmed the importance of cyclical unemployment. While structural unemployment has a depressing effect on fertility across ages, the impact of cyclical unemployment is moderated by age. I find that temporary increases in unemployment early and late in life have a positive influence on fertility, and that temporary reductions in unemployment can have a more ambiguous influence on fertility.

At its very core, the hypothesis of countercyclical fertility hinges on the incompatibility between childbearing and the participation in the labor market. It is often assumed that having a child involves shifting time from paid work to household production. Then, given that the opportunity cost of childbearing is foregone wages, it follows that worsening labor market prospects would lower those opportunity costs. In that sense, the stronger the incompatibility between paid work and childbearing, the larger the potential countercyclical effects of unemployment on fertility. That is, the more likely it is that a temporary increase in unemployment might lead to an increase in fertility. However, even in a context of high barriers to combining childbearing and paid work, a sufficiently high income effect of unemployment could suppress a countercyclical fertility response. Nevertheless, the fact that I do find a countercyclical effect of unemployment on fertility can be interpreted as supportive evidence that conciliation is an important component in explaining fertility levels.

As such, the findings of this paper lends support to policies that reduce the opportunity cost of childbearing. An example of these types of policies include flexible working schedules, maternity and paternity leaves, or public provision or subsidies for day care services. My results contribute to the growing evidence on the importance of conciliation as a determinant of fertility. Traditionally, the expansion of female labor force participation was seen as the main force behind the negative trends in fertility rates. However, recent research has shown that the relationship between participation and fertility might be U-shaped. In country level analysis, high levels of development, often with relatively high levels of female labor participation, have been shown to be associated with relatively high fertility rates (Myrskylä et al. 2009). Some research has pointed that this might be explained by the role of the government in providing means for conciliation in high-income countries (Brewster and Rindfuss 2000). From an individual level perspective, other authors have emphasized the emergence of market provided alternatives to household production. For example, Hazan and Zoabi (2014) report the U-shaped pattern of fertility by education levels and attribute it to the capacity to hire external help.

The results in this paper also have more direct policy implications. The evidence that I provide indicates that structural unemployment has an immediate negative 
effect on fertility that is particularly strong at younger ages. Furthermore, we know that despite evidence that the negative effect corresponds in part to postponement, the overall effect is still negative for completed fertility (Currie and Schwandt 2014). This suggests that fiscal adjustments that result in cutting down on programs aimed at promoting fertility would be particularly harmful for the recuperation of above replacement fertility levels. In contrast, my findings suggest that the short-term unemployment effects on fertility happen in shorter horizons. Therefore, this shortterm fluctuations of unemployment are potentially less likely to have an effect on completed fertility. At the same time, while my work suggests that short-term unemployment might not affect completed fertility for families, it may have adverse effects on the outcomes of children born as a result of countercyclical fertility. Thus far, existing evidence is mixed and context dependent. For example, it is found in the USA (Dehejia and Lleras-Muney 2004) that babies born during recessions have a reduced incidence in a variety of poor health outcomes. The authors claim that part of this positive effect on health could be related to selection into childbearing, which is broadly consistent with the mechanisms described in this work. Other work, in the context of developing countries, finds that economic downturns are associated with higher infant mortality (see for example Bhalotra (2010)).

The results found in this work are gleaned through a cohort model based approach. One reason why cohort models are capable of capturing the countercyclical effects of unemployment on fertility, which have been highlighted in this paper, might be that the previous PtP-based analysis did not allow enough time for the family to distinguish between permanent and temporary variations of unemployment. The underlying hypothesis of my work is that distinguishing between these types of unemployment is actually reflective of the statistical impact of the different types of unemployment on lifelong earnings. However, this is not the only possible mechanism. Radjan (1999) has highlighted the pure effect of income uncertainty in depressing fertility. In this case, uncertainty does not necessarily have to be linked to an actual depression in lifelong earnings. Other work has focused more on the perception of future economic prospects, as measured by consumer confidence indexes (for example, see Fokkema et al. (2008)). It is beyond the scope of this paper to discern the relative importance of all of these mechanisms, but doing so is an important area for future research, as it is likely that not all mechanisms have the same policy implications.

Throughout the paper, the theoretical framework of reference has been the classical unitarian family model, which treats a family as a single decision maker and hence disregards within-family interactions. Nevertheless, family formation and bargaining within existing families are important mechanisms affecting fertility. For example, the delays in marriage associated with economic crisis have been shown to play a role in fertility (Ahn and Mira 2001; Ogawa 2003 and Jones 2007). There is also an extensive literature on interactions within the family unit (for an early reference, see Manser and Brown (1980)). The bargaining process among the couple, molded by institutional arrangements, has been shown to have an impact on both labor force participation decisions and fertility decisions (see Cigno (2012) for a recent theoretical analysis, and Lundberg et al. (2016) for an review of family structures and their consequences). Without disregarding the validity of these frameworks, an analysis of the 
influence of such mechanisms is beyond the scope of this work. The dimension I emphasize in this work is the life cycle perspective, analyzed through the lens of the cohort.

Finally, while the cohort-based approach captures total effects, it also comes with certain costs when estimated in small samples. The first is that because the model is estimated on completed fertility, it does not allow us to distinguish perfectly between direct and indirect effects. Hence, while the cohort model would not incorrectly label a tempo effect as a quantum response, it does not distinguish tempo effects within an age group. In addition, it does not allow us to identify the impact that unemployment in a particular year (instead of across the whole history) might have had on completed fertility. It is important to keep in mind, however, that these two shortcomings are not inherent to the cohort approach, but are rather the results of the compromises that must be made when the model is estimated on a small sample. It is theoretically possible to more accurately distinguish between direct and indirect effects, and to identify the strict timing of the effects simply by adding more variables to summarize the cohort history of unemployment. Thus, investigating the hypothesis of this work in a microeconometric setting is a natural next step.

Acknowledgments Open access funding provided by the Max Planck Society. The author thanks Mikko Myrskylä, Ronald D. Lee, Marc Saez, Hippolyte d'Albis, Adeline Lo, and two anonymous referees for their comments and helpful suggestions. Manja Janowski provided excellent research assistance. All errors are my own.

Open Access This article is distributed under the terms of the Creative Commons Attribution 4.0 International License (http://creativecommons.org/licenses/by/4.0/), which permits unrestricted use, distribution, and reproduction in any medium, provided you give appropriate credit to the original author(s) and the source, provide a link to the Creative Commons license, and indicate if changes were made.

\section{Compliance with Ethical Standards}

Conflict of interests The authors declare that they have no conflict of interest.

\section{Appendix}

This appendix includes tables with a detailed version of the main results in the paper (Table 2), and the results of the robustness checks reported in the paper (Tables 3 and 4). In addition, Table 1 lists the countries and sources used in the paper. While the data in Myrskylä et al. (2013) is cohort based, it was transformed to period-based fertility using the identity period $=$ cohort + age . Table 2 consists of a complete collection of the point estimates and its significance level across model specifications. It contains the results for the PtP, the $\mathrm{CsH}$, and the $\mathrm{CwH}$ models. The columns show the results for the different age groups, and the results of the models are in the rows.

Tables 3 and 4 show a comparison of the significance levels across robustness checks, as compared to those of the PtP and the $\mathrm{CsH}$ models. The results in Table 3 are from the standard models in the first two columns ( $\mathrm{PtP}$ and $\mathrm{CsH}$ ), and then from the $\mathrm{CsH}$ models with different variable definitions and samples. The first four columns remove, in turn, Japan, the USA, Spain, and Australia from the sample. The last two columns use only gender-specific unemployment; male and female 
separately. Table 4 displays the results of the $\mathrm{CsH}$ models that use age-specific unemployment rates. The unemployment and participation series are available online from statistical repository of the OECD in the labor section, then labor force statistics, and finally the sex and age disaggregation. Data on age-specific unemployment and

Table 2 Detailed results from period-to-period, cohort-sans-history, and cohort-with-history models

\begin{tabular}{|c|c|c|c|c|c|}
\hline \multirow{2}{*}{$\begin{array}{l}\text { Models } \\
\text { Variables }\end{array}$} & \multicolumn{5}{|c|}{ Fertility by age group } \\
\hline & 15 to 19 & 20 to 24 & 25 to 29 & 30 to 34 & 35 to 39 \\
\hline \multicolumn{6}{|c|}{ Period-to-period } \\
\hline Time & $-0.0021 * *$ & $-0.0093 * *$ & $-0.0063^{* *}$ & $0.0078 * *$ & $0.0056^{* *}$ \\
\hline Trend & $-0.0031 * *$ & $-0.0152^{* *}$ & $-0.0090^{* *}$ & $-0.0104 * *$ & $-0.0108 * *$ \\
\hline Pos. cycle & 0.0004 & 0.0088 & 0.0165 & $0.0162 *$ & $0.0073 \dagger$ \\
\hline Neg. cycle & 0.0006 & -0.0036 & 0.0099 & 0.0028 & $-0.0087^{* *}$ \\
\hline \multicolumn{6}{|c|}{ Cohort sans history } \\
\hline Time & $-0.0046^{* *}$ & $-0.0092^{* *}$ & $-0.0111^{* *}$ & $0.0038 * *$ & $0.0062 * *$ \\
\hline Trend & -0.0009 & $-0.0208^{* *}$ & $0.0076^{* *}$ & $-0.0127^{* *}$ & $-0.0045^{* *}$ \\
\hline Pos. cycle & $0.0024 * *$ & 0.0060 & 0.0007 & $0.0037 * *$ & $0.0020 * *$ \\
\hline Neg. cycle & 0.0031 & 0.0007 & $0.0066 * *$ & $-0.0090 * * *$ & -0.0003 \\
\hline \multicolumn{6}{|c|}{ Cohort with history } \\
\hline Time & $-0.0046^{* *}$ & $-0.0060 * *$ & $-0.0097 * *$ & $0.0034 * *$ & $0.0061 * *$ \\
\hline \multicolumn{6}{|l|}{ Trend } \\
\hline 15 to 19 & -0.0009 & $-0.0136^{* *}$ & 0.0001 & $0.0042 * *$ & 0.0014 \\
\hline 20 to 24 & - & $-0.0087^{* *}$ & -0.0067 & $-0.0035 \dagger$ & 0.0004 \\
\hline 25 to 29 & - & - & $0.0213 *$ & 0.0022 & 0.0009 \\
\hline 30 to 34 & - & - & - & $-0.0121 * *$ & $-0.0023^{*}$ \\
\hline 35 to 39 & - & - & - & - & -0.0031 \\
\hline \multicolumn{6}{|l|}{ Positive cycle } \\
\hline 15 to 19 & $0.0024 * *$ & $0.0083 * *$ & - & - & \\
\hline 20 to 24 & - & -0.0004 & $-0.0102 * *$ & - & - \\
\hline 25 to 29 & - & - & -0.0107 & -0.0024 & - \\
\hline 30 to 34 & - & - & - & 0.0030 & $0.0025^{*}$ \\
\hline 35 to 39 & - & - & - & - & 0.0024 \\
\hline \multicolumn{6}{|c|}{ Negative cycle } \\
\hline 15 to 19 & 0.0031 & 0.0024 & - & - & - \\
\hline 20 to 24 & - & 0.0015 & $-0.0167 \dagger$ & - & - \\
\hline 25 to 29 & - & - & 0.0043 & $0.0076^{* *}$ & - \\
\hline 30 to 34 & - & - & - & 0.00004 & -0.0003 \\
\hline 35 to 39 & - & - & - & - & 0.0002 \\
\hline
\end{tabular}

${ }^{* *} p<0.05$

${ }^{*} p<0.1$

${ }^{\dagger} p<0.15$ 


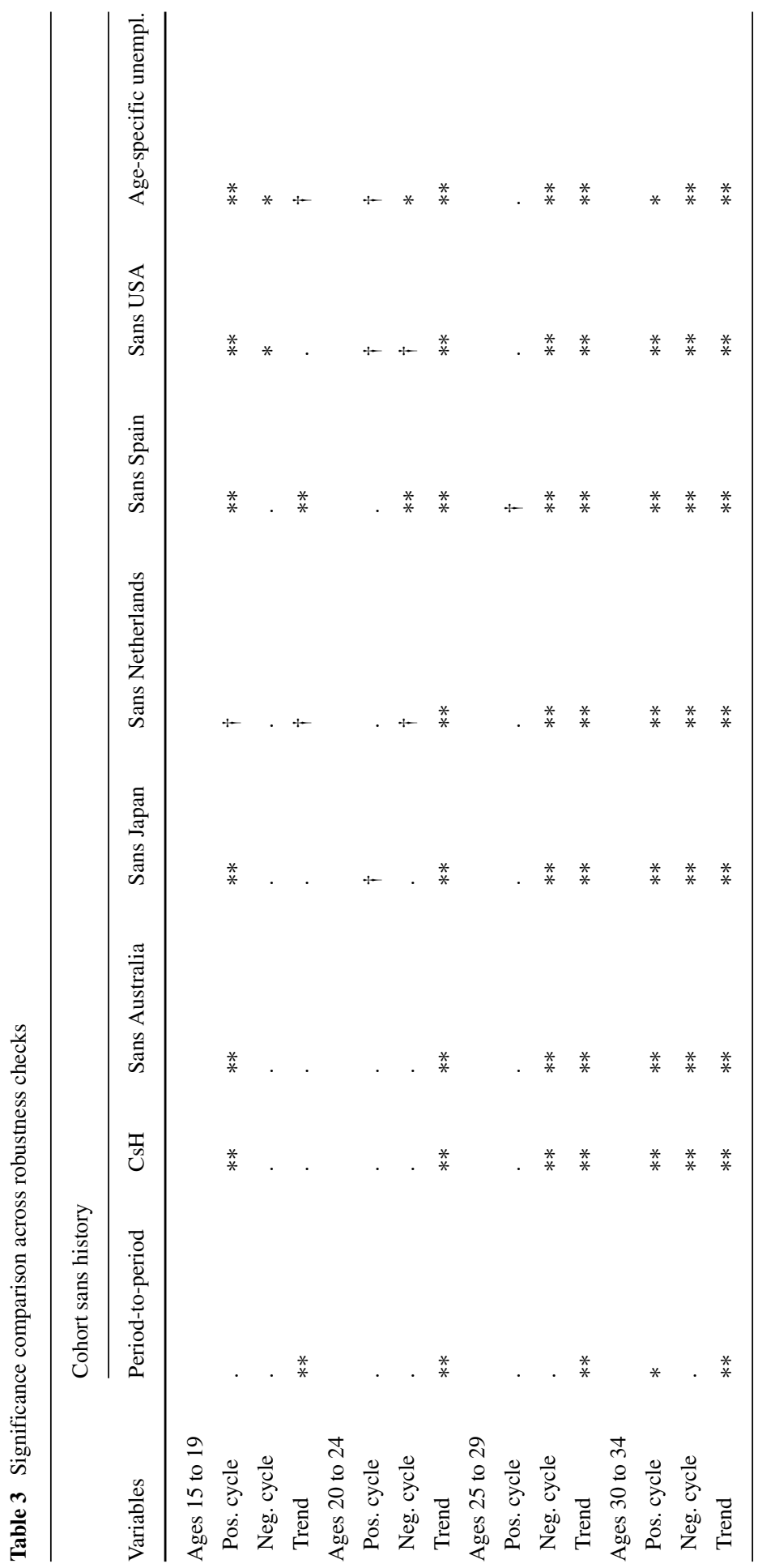




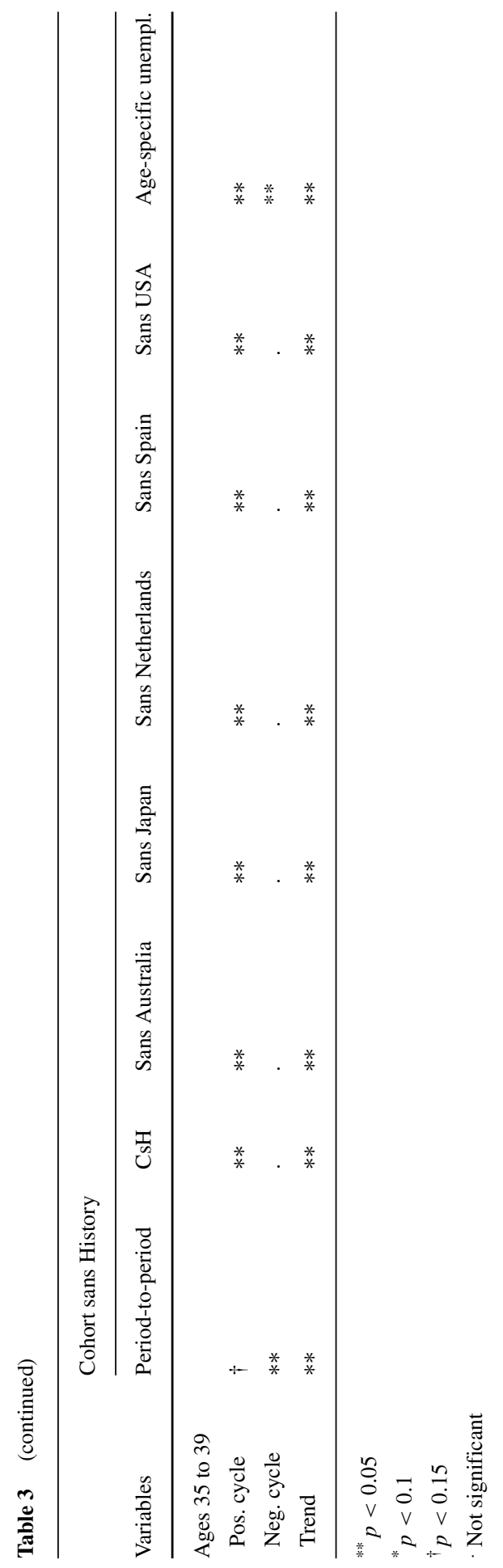




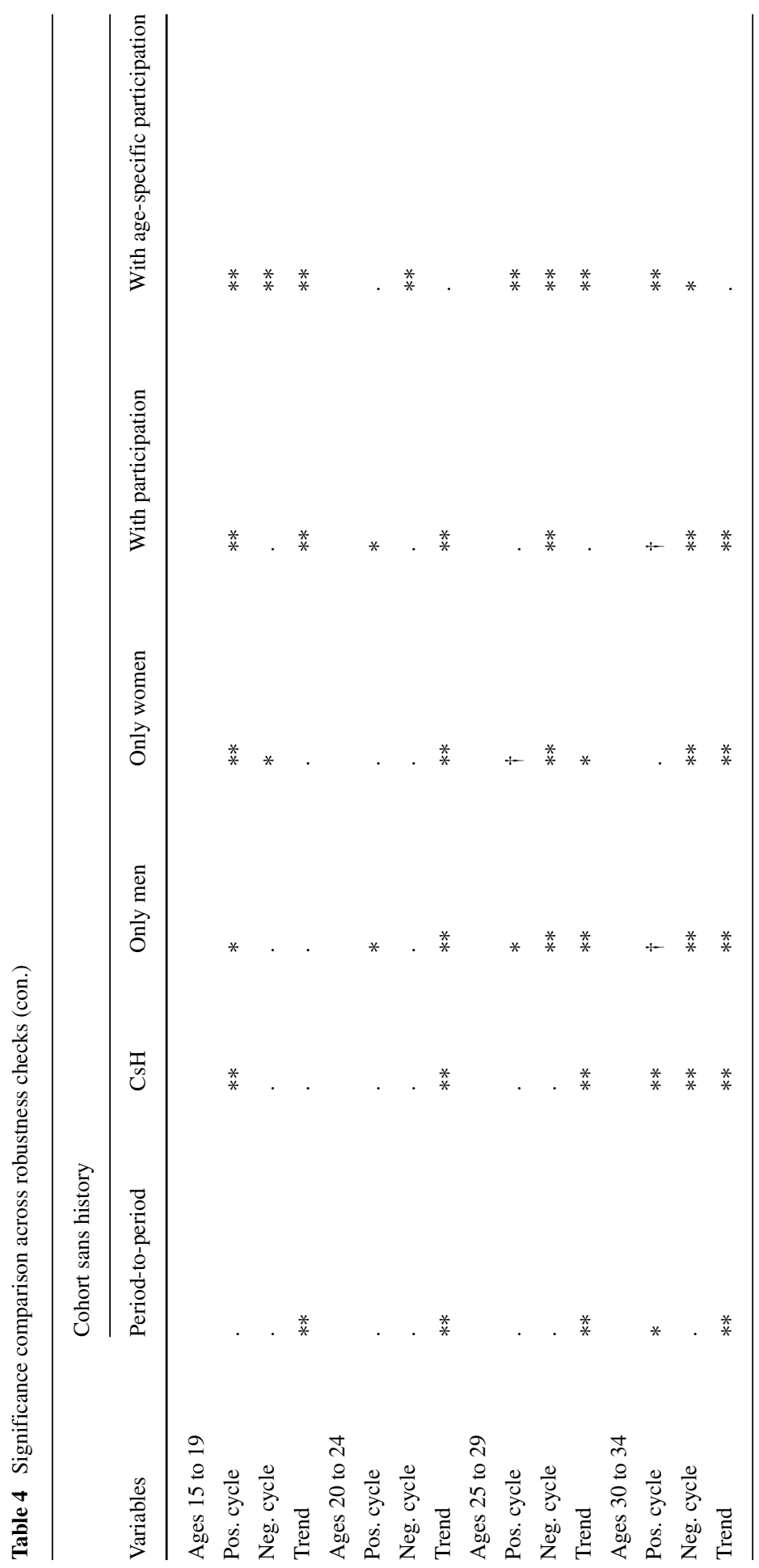




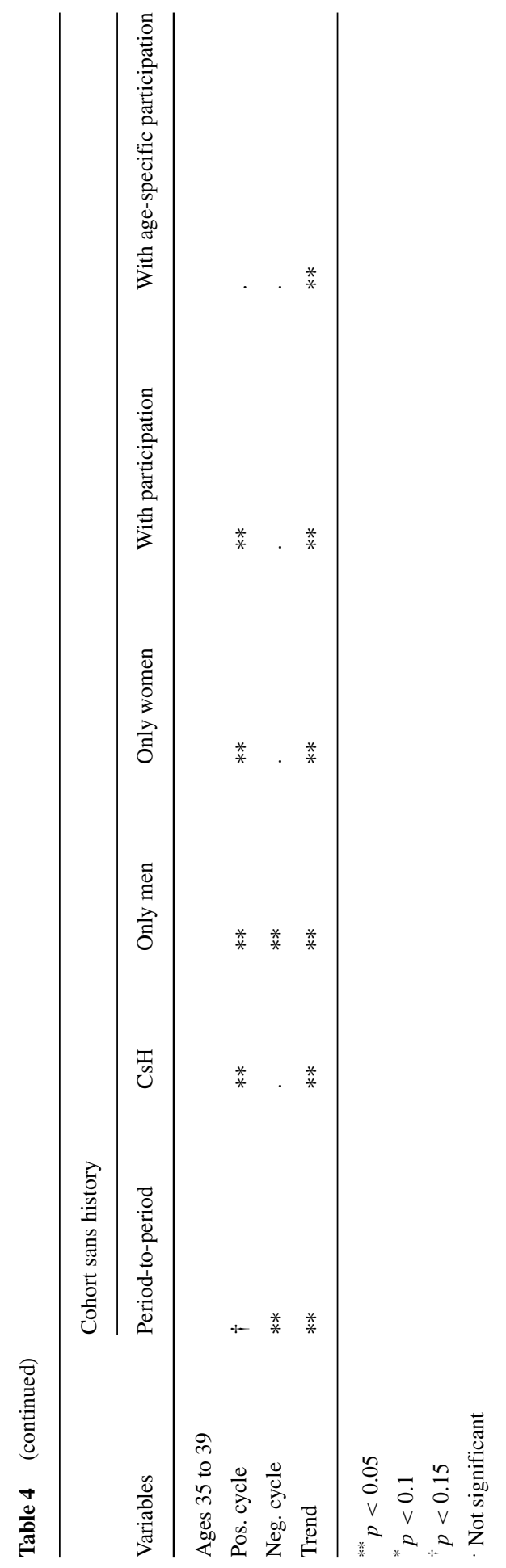




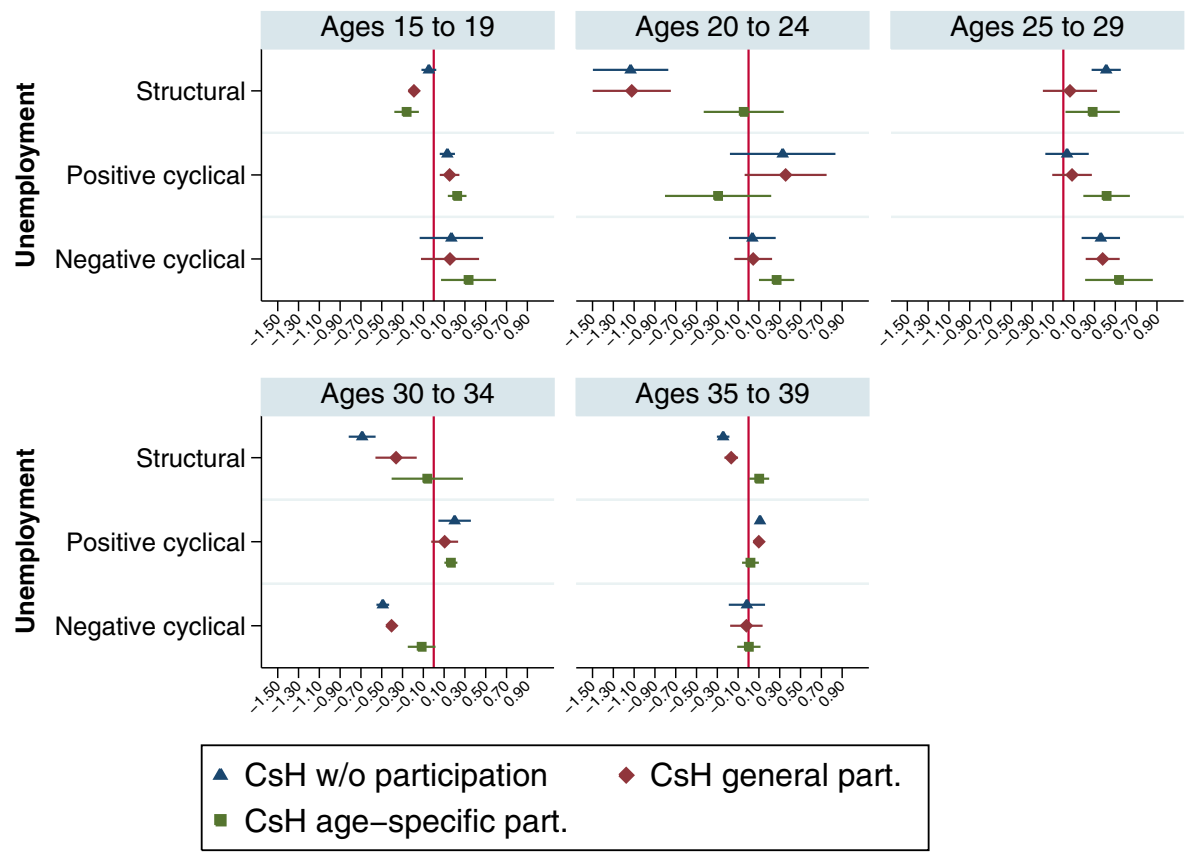

Fig. 8 Effect of unemployment with respect to average cohort completed fertility in $\mathrm{CsH}$ models controlling for labor participation. Lines represent $95 \%$ confidence intervals and dots point estimates

participation are not available for the Netherlands and hence this country is dropped in those specific robustness checks.

\section{References}

Abel AB (2001) Will bequests attenuate the predicted meltdown in stock prices when baby boomers retire? Rev Econ Stat 83(4):589-595

Adserà A (2004) Changing fertility rates in developed countries. The impact of labor market institutions. J Popul Econ 17(1):17-43

Adserà $\mathrm{A}$ (2005) Vanishing children: from high unemployment to low fertility in developed countries. Am Econ Rev 95(2):189-193

Ahn N, Mira P (2001) Job bust, baby bust?: evidence from Spain. J Popul Econ 14(3):505-521

Ahn N, Mira P (2002) A note on the changing relationship between fertility and female employment rates in developed countries. J Popul Econ 15(4):667-682

Andersson G (2000) The impact of labour-force participation on childbearing behaviour: pro-cyclical fertility in Sweden during the 1980s and the 1990s. Eur J Popul 16(4):293-333

Becker GS (1965) A theory of the allocation of time. Econ J 75(299):493-517

Becker GS (1981) A treatise on the family. Harvard University Press, Cambridge

Bhalotra S (2010) Fatal fluctuations? Cyclicality in infant mortality in India. J Dev Econ 93(1):7-19

Breusch TS, Pagan AR (1979) A simple test for heteroscedasticity and random coefficient variation. Econometrica 47(5):1287-1294

Breusch TS, Pagan AR (1980) The Lagrange multiplier test and its application to model specification in econometrics. Rev Econ Stat 47(1):239-254

Brewster KL, Rindfuss RR (2000) Fertility and women's employment in industrialized nations. Annu Rev Sociol 26:271-296 
Butz W, Ward M (1979) The Emergence of countercyclical US fertility. Am Econ Rev 69(3):318-328

Cigno A (2012) Marriage as a commitment device. Rev Econ Household 10(2):193-213

Currie J, Schwandt H (2014) Short- and long-term effects of unemployment on fertility. P Natl Acad Sci Usa 111(41):14734-14739

Dehejia RH, Lleras-Muney A (2004) Booms, busts, and babies' health. Q J Econ:1091-1130

Driscoll JC, Kraay AC (1998) Consistent covariance matrix estimation with spatially dependent panel data. Rev Econ Stat 80(4):549-560

Ermisch J (1988) Econometric analysis of birth rate dynamics in Britain. J Hum Resour 23(4):563-576

Fokkema T, de Valk H, de Beer J, van Duin C (2008) The Netherlands: childbearing within the context of a "Poldermodel" society. Demogr Res 19:774-776

Goldstein JR, Kreyenfeld M, Jasilioneine A, Karaman Örsal D (2013) Fertility reactions to the "Great Recession" in Europe: recent evidence from order-specific data. Demogr Res 29:85-104

Hazan M, Zoabi H (2014) Do highly educated women choose smaller families? Econ J 125(587):11911226

Heckman JJ (2015) Introduction to a theory of the allocation of time by Gary Becker. Econ J 0(583):403409

Hoechle D (2007) Robust standard errors for panel regressions with cross-sectional dependence. Stata J $7(3): 281-312$

Hoem B (2000) Entry into motherhood in Sweden: the influence of economic factors on the rise and fall in fertility, 1986-1997. Demogr Res 2(4):1-28

Hotchkiss JL, Pitts MM (2007) The role of labor market intermittency in explaining gender wage differentials. Am Econ Rev 97(2):417-421

Hodrick RJ, Prescott EC (1997) Postwar U.S. business cycles: an empirical investigation. J Money Credit Bank 29(1):1-16

Jones GW (2007) Delayed marriage and very low fertility in pacific asia. Popul Dev Rev 33(3):453-478

Kögel T (2004) Did the association between fertility and female employment within OECD countries really change its sign? J Popul Econ 17(1):45-65

Lee R (1973) Population in preindustrial England: an econometric analysis. Q J Econ 87(4):581-607

Lindo JM (2010) Are children really inferior goods? Evidence from displacement-driven income shocks. J Hum Resour 45(2):301-327

Lundberg S, Pollak RA, Stearns J (2016) Family inequality: diverging patterns in marriage, cohabitation, and childbearing. J Econ Perspect 30(2):79-101

Manser M, Brown M (1980) Marriage and household decision-making: a bargaining analysis. Int Econ Rev 21(1):31-44

McDonald J (1983) The emergence of countercyclical US fertility: a reassessment of the evidence. J Macroecon 5(4):421-436

Mincer J (1962) Labor force participation of married women: a study of labor supply. In: Mincer J. Aspects of labor economics. Princeton University Press, pp 61-105

Murphy KM, Topel R (1997) Unemployment and nonemployment. Am Econ Rev 87(2):295-300

Myrskylä M, Kohler HP, Billari FC (2009) Advances in development reverse fertility declines. Nature 460:741-743

Myrskylä M, Goldstein JR, Cheng YHA (2013) New cohort fertility forecasts for the developed world: rises, falls, and reversals. Popul Dev Rev 39(1):31-56

Neels K, Theunynck Z, Wood J (2013) Economic recession and first births in Europe: recession-induced postponement and recuperation of fertility in 14 European countries between 1970 and 2005 . Int J Public Health 58(1):43-55

Ogawa N (2003) Japan's changing fertility mechanisms and its policy responses. J Popul Res 20(1):89-106

Oreopoulos P, von Wachter T, Heisz A (2012) The short-and long-term career effects of graduating in a recession. Am Econ J 4(1):1-29

Poterba JM (2001) Demographic structure and asset returns. Rev Econ Stat 83(4):565-584

Radjan P (1999) Fertility behaviour under income uncertainty. Eur J Popul 15(1):25-43

Ravn MO, Uhlig H (2002) On adjusting the Hodrick-Prescott filter for the frequency of observations. Rev Econ Stat 84(2):371-376

Sobotka T, Skirbekk V, Philipov D (2011) Economic recession and fertility in the developed world. Popul Dev Rev 37(2):267-306

Wooldridge JM (2002) Econometric analysis of cross section and panel data. MIT Press, Cambridge 